\title{
Risk Assessment in the Shipbuilding Industry: Present and the Future
}

\author{
Byung Yong Jeong, Woo Jin Kim, Ye Seul Jeong \\ Department of Industrial and Management Engineering, Hansung University, Seoul, 136-792
}

\begin{abstract}
Objective: The aim of this study is to gain an overview of the risk assessment and management system in the shipbuilding industry. Background: The use of risk assessment techniques has grown significantly in recent years. Method: Various references have been reviewed to evaluate risk assessment and management policy. Results: Adapting the risk assessment system has become an important approach not only to prevent industrial accidents but also to enhance the efficiency of works for shipbuilding workers. Conclusion: Risk assessment is an approved technology for operators to address larger hazards, and to ensure risks have been reduced to appropriate levels cost effectively. Application: These results can be used to provide baseline information for risk assessment and management policy.
\end{abstract}

Keywords: Risk assessment, Shipbuilding industry, Matrix ranking assessment

\section{Introduction}

조선업은 실외나 고소 작업, 밀폐 공간 등에서 폭발성 물 질이나 유해물질, 중량물 취급 작업이 많고, 작업 공정이 다 양하여 빈번하게 작업장을 이동할 뿐만 아니라 규모가 방대 하고 설비의 설치/해체 작업 등으로 인하여 사고 위험요인이 많이 존재한다. 이러한 특성 때문에 2010년 조선업종의 재 해율은 전체 산업의 재해율 보다 약 1.74 배 높게 나타났다 (KOSHA, 2011).

조선업종에서의 높은 재해율은 보험료의 증가를 가져오고, 기업의 이미지를 떨어뜨릴 뿐만 아니라 건조되는 제품의 품 질에 영향을 미칠 수 있으며, 국제적인 수주 경쟁에서의 경 쟁력을 약화시키는 요인이 될 수 있다. 조선업종의 높은 재 해율을 낮추기 위해 정부에서는 2002년 조선업 차등 관리 제도를 시행하였으며, 2005년에는 Safe Ship Program을 실시하였다. 국내의 각 조선 회사에서는 국제적인 경쟁력을 확보하기 위하여 KOSHA 18001, ISO 14001, OHSAS 18001 등의 안전보건환경경영체제를 구축하였으며, 위험성
평가를 통하여 위험요소를 사전에 파악하고 적절한 예방과 개선활동을 펼침으로써 재해를 체계적으로 관리하려고 노력 하고 있다(KOSHIPA, 2011).

한편, 정부는 현행 산업안전보건법으로는 산업환경의 변화 와 다양한 위험요인의 관리에 한계가 있다고 판단하고, 이에 대한 해결책으로 위험성 평가제도를 2009년에 도입하였다 (Park, D.Y. et al., 2009). 위험성 평가제도는 사업장내 위 험요인을 잘 아는 노사가 협력하여 지속적으로 위험요인을 발굴하고 개선함으로써 근원적으로 사고를 예방하고자 하는 종합적인 안전관리 활동이다.

본 연구에서는 우리 나라에서 진행된 위험성 평가에 관한 연구들을 분석하여 위험성 평가제도의 본질과 현황을 파악 하고자 한다. 특히, 조선업종에서의 위험성 평가제도의 운영 실태와 문제점 등을 파악하여 우리 나라에서의 위험성 평가 제도 도입에 관한 선행조건과 해결하여야 할 과제들을 검토 하여 보고자 한다.

Corresponding Author: Byung Yong Jeong. Department of Industrial and Management Engineering, Hansung University, Seoul, 136-792. Phone: 02-760-4122, E-mail: byjeong@hansung.ac.kr

Copyright@2012 by Ergonomics Society of Korea(pISSN:1229-1684 eISSN:2093-8462). All right reserved. 


\section{Literature Survey}

\subsection{Risk assessment methods}

위험성 평가는 위험요인을 찾아내고 추정하는 위험분석 (risk analysis), 위험 수용성 판정기준에 근거한 위험도 평 가 및 위험감소 전략제거 방안을 도출하는 위험성 평가(risk assessment), 비용분석을 통한 위험감소 전략제거 방안의 결정 및 시행에 대한 위험관리(risk management) 단계로 구분할 수 있다(HSE, 2002).

위험성 평가에서 위험을 분석하는데 이용되는 기법으로는 정성적 위험성 평가와 정량적 위험성 평가로 구분된다(HSE, 2000).

정량적 위험성 평가는 화학업종이나 원자력분야 등과 같 이 정확한 위험도를 예측하기 위한 목적으로 이용된다. 정량 적 위험성 평가 기법을 적용한 연구로는 Kim, Y.H. et al. (1997)의 FTA(Fault Tree Analysis)를 이용한 화학공장 의 위험성 평가 및 응용과 Che, G.S.(1999)의 FTA 기법 에 의한 원전기동전원의 이용율 예측에 관한 연구, 이 밖에 도 Chung, J.H. et al.(1999)은 EPS 공정의 정량적 위험성 평가 연구에서 ETA(Event Tree Analysis)와 FTA 기법 을 적용하였고, Jang, S.I. et al.(2001)은 정량적 위험성 평 가에 의한 안전관리 투자의 비용 연구에서 FTA와 CA 기법 을 적용하였다.

정성적 위험성 평가는 사업장에서 위험을 발견하고 위험 도를 예측하여 위험요소를 감소시키기 위한 개선활동으로 연계되어 활용된다. 정성적 위험성 평가 연구를 살펴보면 건 설현장 전력설비에 대하여 FMEA(Failure Mode Effects Analysis)를 적용한 Kim, D.H. and Lee, J.H.(2004)의 연 구, $\mathrm{AHP}$ (Analytic Hierarchy Process) 기법을 적용한 Kim, J.G. and Chung, J.H.(2004)의 연구, 제철 사업장을 대상으 로 한 Hong, S.M. et al.(2009) 의 연구, $4 \mathrm{M}$ 기법을 적용한 Jeong, B.Y. et al.(2008)의 연구, AMEA (Accident Mode and Effects Analysis)를 적용한 Kim, G.H. et al.(2007) 의 연구, 산업용기계류의 정성적 평가 기법을 전반적으로 소 개한 Lee, J.Y. et al.(2010) 연구 등이 있다.

\subsection{Risk assessment system and policy}

위험성 평가 관련 제도에 대한 연구로는 중소규모 사업장 의 자율안전보건경영체제 구축방안을 제시한 Kim, T.O. et al.(2007)의 연구, 미국, 영국, 독일, 호주 등 외국의 위험성 평가제도 운용사례를 조사하고 국내의 제도 운용 가능성을 제시한 Lee, Y.S. et al.(2007)의 연구, 각국의 위험성 평가 제도의 비교와 국내 위험성 평가제도 도입방안에 관한 Park,
D.Y. et al.(2009)의 연구, 위험성 평가제도를 정착시키기 위한 산업안전보건법 행정체계 및 집행체계에 관한 Park, D.Y. et al.(2010)의 연구 등이 있다.

위험성 평가제도의 도입은 기술적인 측면에서 새로운 제 도를 도입한다는 의미뿐만이 아니라 법률적인 패러다임의 전환을 뜻하는 종합적인 변화를 의미한다. 유럽에서 위험성 평가제도가 정착되기까지는 1981 년 ILO 국제협약을 기점으 로 20 년이 걸렸다. 시대적으로 유럽 국가를 지 탈규제 현상 에 맞추어 규제를 합리화하고 유연화 하겠다는 위험성 평가 제도의 철학이 정립되었다고 볼 수 있다. 일을 하는 모든 장 소와 모든 근로자가 법의 적용을 받도록 하고, 위험성 평가 를 할 때 객관적 기준은 법적인 규제를 하되 나머지는 노사 의 결정에 맡겨서 사용자와 근로자가 함께 책임을 부담하는 시스템으로 정착된 것이다. 영국의 위험성 평가제도에서 위 험성 평가의 책임은 사업주에게 부과되고 있으며, 업무 중 발생되는 위험성을 평가하여 위험성에 필요한 조치를 취하 도록 요구하고 있다. 그 평가의 대상으로는 작업활동에 의해 영향을 받을 수 있는 모든 사람으로 규정하고 있으며, 새로 운 작업을 시작하기 전에 평가하여 위험성 평가 결과를 기 록하도록 하고 필요할 때에 보완하도록 하고 있다. 영국의 위험성 평가 절차로는 $5 \mathrm{Step}$ 이라는 평가 순서를 갖고 있으 며 이에 맞춘 평가 양식을 사용하고 있다(HSE, 1998). 독 일의 경우에는 위험성 평가법의 목표를 단순한 사고예방이 아니라 헌법정신에 따라 사람을 보호하고 신체적 이상이 발 생되지 않도록 함으로써 사고 및 건강장해, 직업병 등을 예 방하고, 인간성 존중의 측면에서 인간에게 알맞은 근로조건 마련을 추구하고 있다. 위험성 평가에 대한 책임은 영국과 마찬가지로 사업주에게 부과하고 있으며, 평가 결과를 문서 화 하여 근로자에게 제공함으로써 근로자의 참여를 유도하 고 있다(Park, D.Y. et al., 2009).

국내에서는 산업안전보건법 내의 유해화학물질의 위험성 평가제도, 공정안전보고서 작성 및 제출제도, 유해위험방지 계획서 작성 및 제출, 안전보건진단제도, 작업환경측정제도, 근골격계 부담작업에 대한 유해요인 조사 등의 위험성 평가 에 근간을 둔 제도가 도입되었으며, 2009년 2월 개정된 산 업안전보건법 제 5 조 1 항에는 위험성 평가제도의 핵심인 사 업주의 위험성 평가의무가 도입되었다.

조선업종의 위험성 평가에 관한 연구로는 Jeong, B.Y. et al.(2007a)의 평가자 관점에서의 위험성 평가제도에 관한 연구, Jeong, B.Y. et al.(2007b)의 조선업 재해 유형에 따 른 위험성 평가자료의 분석, Jeong, B.Y. et al.(2008)의 조 선회사의 위험성 평가제도의 현황과 평가모델 개발, $\mathrm{SeO}$, J.M. et al. (2007)의 조선업 위험성 평가 프로그램 모델 개 발 연구, Chang, S.R. et al.(2008)의 조선업 위험성 평가 결 과에 대한 자체감사 모델 개발 연구, Lim, H.K. et al.(2011) 
의 중소규모조선업 사업장을 위한 자율 위험성 평가 모델 연 구 등이 있다.

\section{The Process of Risk Assessment}

\subsection{Overall concept of risk assessment}

위험성 평가는 Figure 1 과 같이 자율적으로 위험요인을 찾아내고, 위험 수용성 판정기준과 위험도에 따라 위험감소 방안의 우선순위를 결정한 뒤, 개선안을 시행하는 절차로 진 행된다(HSE, 2002).

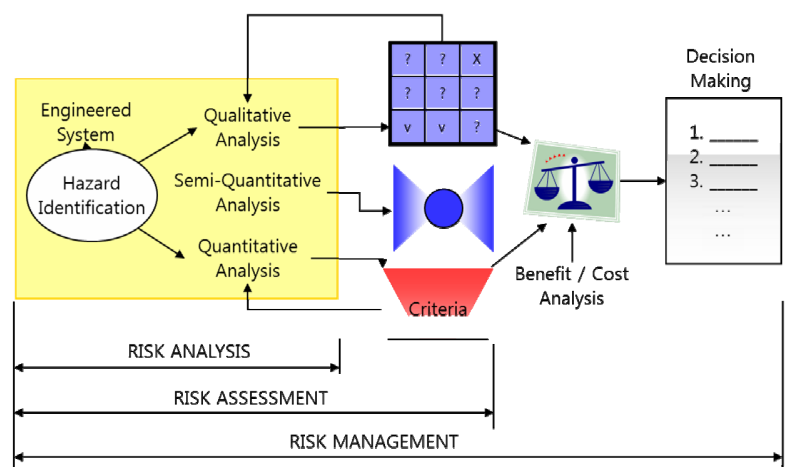

Figure 1. Risk management procedures(HSE, 2002)

근로자가 자율적으로 위험요인을 파악하고 제거하기 위한 활동을 강조하는 현장 개선형 위험성 평가는 이용하기 쉽고, 편한 절차가 필수적으로 요구된다. 본 장에서는 현장 중심의 위험성 평가에 주로 사용되는 위험도 매트릭스 기법(risk matrix method)을 중심으로 위험성 평가 절차 및 원리를 살펴보고자 한다.

일반적으로 위험도는 위험의 강도와 빈도로써 표현한다. 위험의 강도와 빈도의 수준은 평가자가 주관적으로 부여하 거나, 정해진 정량적인 판정기준에 의해 부여한다. 주로 서 열척도를 이용하여 3 등급 $(\mathrm{H}: 1$ 점, $\mathrm{M}: 2$ 점, $\mathrm{L}: 3$ 점)에서 5등 급으로 표현한다. Figure 2 는 강도와 빈도가 각각 3 등급으로 정의된 위험요인들에 대한 위험도를 빈도와 강도의 합과 곱 으로 나타낸 예이다.

Figure 2에서 보면 빈도와 강도가 각각 높은(H: 3점) 경 우에는 위험도가 6 점 $(=3+3)$ 또는 9 점 $(=3 * 3)$ 으로 표현됨 을 볼 수 있다. 위험도를 빈도와 강도의 합으로 표현할지 곱 으로 표현할지에 관한 문제는 회사의 상황이나 위험요인의 여건을 반영하여 정하게 된다.

위험도 점수에 따라 위험의 수용여부에 관한 관리기준은
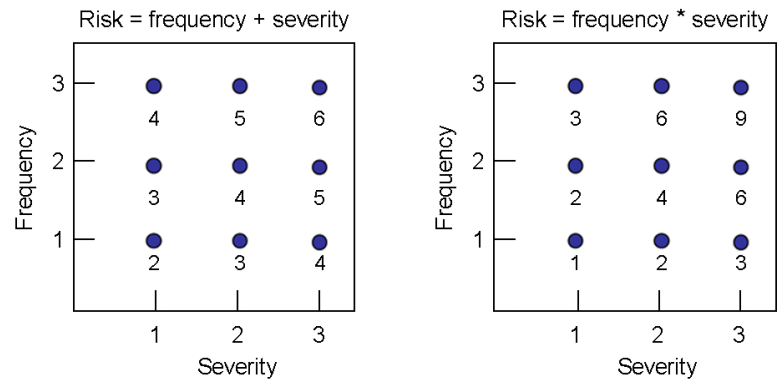

Figure 2. Risk based on frequency and severity

Table 1 과 같이 3 등급이나 5등급이 주로 사용되며, 위험 수 준에 따라 특정 위험 수준의 등급 이상에 대해서는 개선 계 획을 세우고 위험감소활동을 시행하게 된다.

위험 수준을 3 등급으로 분류하는 경우에는 위험 수용(1등 급), 조건부 위험 수용(2등급), 위험 불허(3등급)로 분류한 다. Table 1 에서와 같이 5 등급으로 위험 수준을 분류하는 경우에는 위험 수준 1 등급(무시할 정도의 위험), 2 등급(수용 가능한 위험)은 위험성을 수용하며 현 상태로 계속 작업이 가능하다. 3 등급(온건한 위험), 4 등급(큰 위험)은 조건부 위험 수용으로, 현재 위험이 나타나지 않으면 계속 작업이 가능하지만 위험감소 활동을 실시하여야 한다. 5 등급(허용할 수 없는 위험)은 위험 불허로 즉시 작업을 중지하여야 한다.

Table 1. Risk tolerability and decision making criteria

\begin{tabular}{c|l|c|c}
\hline Class & Tolerability & Class & Risk criteria \\
\hline 1 & Negligible & \multirow{2}{*}{1} & \multirow{2}{*}{ Acceptable } \\
\hline 2 & Broadly acceptable & & \\
\hline 3 & Moderate & 2 & Tolerable \\
\hline 4 & Severe & & \\
\hline 5 & Intolerable & 3 & Unacceptable \\
\hline
\end{tabular}

Figure 2와 Table 1의 내용을 정리하면 Figure 3과 같이 표현될 수 있다.
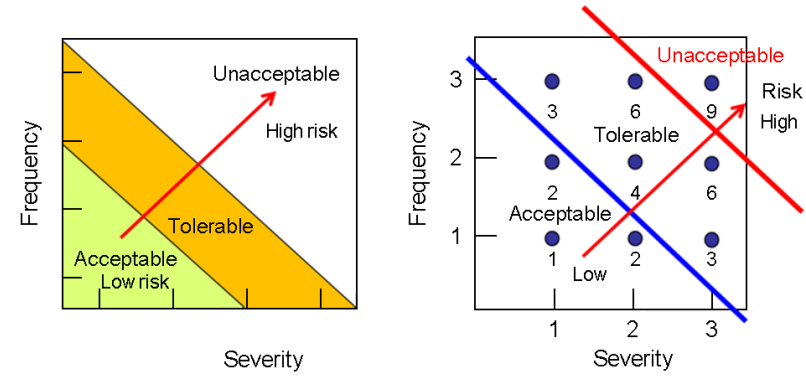

Figure 3. Risk and action criteria 
빈도나 강도는 회사의 여건에 따라 3점 또는 5점 척도의 등급으로 표현되고, 위험도를 빈도와 강도의 곱으로 표현하 면 위험도를 기준으로 수용 가능한 위험 등급부터 허용할 수 없는 위험 등급까지 영역을 분리하여 표현할 수 있다. 위험 성 평가에서는 빈도와 강도의 등급을 어떻게 정하고 몇 개 의 수준으로 나누며, 위험도를 어떻게 표시하느냐, 위험도에 따라 관리 수준을 몇 등급으로 나누는가, 개선 조치 사항은 어떻게 연계시키는가에 대한 내용이 의사결정 변수라고 할 수 있다.

\subsection{Current status in the shipbuilding industry}

글로벌 시장에서 선박을 의뢰하는 해외 선주사들은 선박 제조 회사들에게 안전보건환경체제 인증을 요구하고 있다. 우리 나라의 대규모 조선 회사들은 선박수주에 필요한 안전 성을 확보하기 위하여 KOSHA 18001, ISO 14001, OHSAS 18001 등의 안전 · 보건 경영시스템 체제를 구축하고 위험 성 평가를 실시하고 있다.

조선업종에서 시행되고 있는 회사별 위험성 평가의 시행 빈도는 정기적으로 시행하는 정기 위험성 평가는 연간 1 회 부터 3년에 1회 빈도로 시행되고 있으며, 수시 위험성 평가 는 재해가 발생하거나 신규 설비나 공정을 도입할 때 시행된 다. 위험성 평가의 주체는 최근 현장 근로자 중심으로 위험 성 평가를 시행하려는 시도가 있지만, 주로 해당 부서의 장 이 주관하거나 위험성 평가 팀을 구성하여 시행을 하고 있 다. 위험성 평가 절차는 안전보건부서에서 주관하여 정하게 되는데 위험성 평가 계획수립, 평가 팀 구성 및 평가자 교육, 위험성 평가 및 중요 위험공정 선정, 개선대상 위험공정의 관리, 검토 및 평가 순으로 구성된다.

Figure 4 는 매트릭스법을 기반으로 조선회사에서 시행되

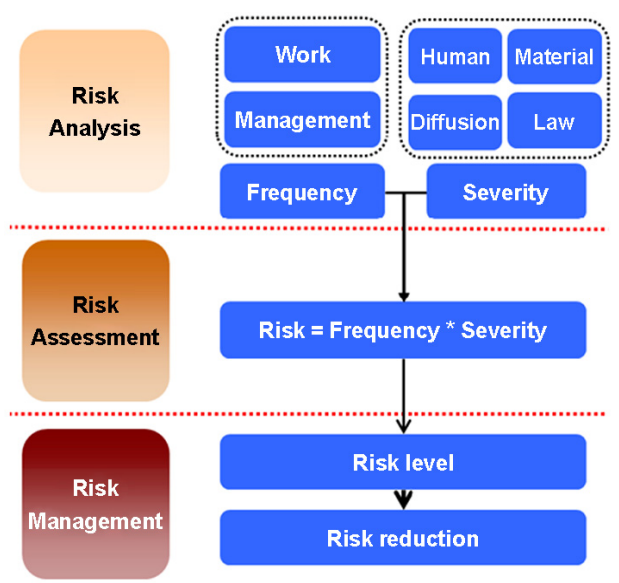

Figure 4. Risk assessment in the shipbuilding industry
고 있는 위험성 평가의 절차를 나타낸 것으로 위험분석과 위험평가, 위험관리 단계로 진행된다(Jeong, B.Y. et al., 2008).

위험분석 단계에선 위험 작업을 위험 빈도와 위험 강도로 분석하는 단계이다. 위험 빈도는 아차 사고, 산재발생 현황, 근골격계질환 유발 가능성 등을 기초로 나타내거나, 작업 빈 도나 관리 대책에 따른 발생 가능성 등으로 평가하여 표현한 다. 평가자는 일반적으로 위험 빈도를 3 등급 $(\mathrm{H}, \mathrm{M}, \mathrm{L})$ 중의 한 등급으로 직접 평가한다. 그러나 Table 2 와 같이 위험 빈 도에 영향을 미치는 변수를 정한 후, 예를 들면 작업 빈도와 관리 대책 두 가지 요인에 따라 등급 기준을 각각 평가한 후 작업 빈도와 관리 대책 등급의 곱으로 표현된 위험 빈도 점 수로서 위험 빈도 등급을 구하기도 한다.

Table 2. Risk frequency using work frequency and condition

\begin{tabular}{c|c|c|c|c|c|c}
\hline \multirow{2}{*}{$\begin{array}{c}\text { Risk frequency } \\
\text { Score / risk level }\end{array}$} & \multicolumn{5}{|c}{ Work condition } \\
\cline { 2 - 7 } \multicolumn{2}{c|}{} & 1 & 2 & 3 & 4 & 5 \\
\hline \multirow{3}{*}{$\begin{array}{c}\text { Work } \\
\text { frequency }\end{array}$} & 1 & $1 / 1$ & $2 / 1$ & $3 / 1$ & $4 / 1$ & $5 / 2$ \\
\cline { 2 - 7 } & 2 & $2 / 1$ & $4 / 1$ & $6 / 2$ & $8 / 2$ & $10 / 3$ \\
\cline { 2 - 7 } & 3 & $3 / 1$ & $6 / 2$ & $9 / 3$ & $12 / 3$ & $15 / 3$ \\
\hline
\end{tabular}

위험 강도의 평가도 피해의 영향을 받을 인체 부위, 피해 의 성격, 유해물질의 인체에 미치는 영향, 작업손실일수 등 을 고려하여 3 등급이나 4 등급으로 평가하는 것이 일반적이 다. 그러나 Figure 4 와 같이 인체 피해, 물적 피해, 피해 확 산, 법적 적용 등의 요인을 등급으로 부여한 후 매트릭스 방 법으로 위험 강도의 등급을 구하기도 한다.

조선회사들은 주로 위험 평가 단계에서 위험 수준을 빈도 와 강도를 매트릭스 기법을 이용하여 평가한다. 즉, 도출된 위험 수준을 기준으로 위험을 수용하여 아무런 조치를 취하 지 않고 작업을 허용하는 등급과 계속 작업을 하되 위험요인 공정으로 등록하여 위험감소 활동을 실시하는 조건부 위험 성 수용 등급으로 분류한다. 위험성 불허 등급은 중대한 위 험성을 포함한 공정으로 개선이 되기 전까지는 즉시 작업을 중지하여야 할 위험 수준을 의미한다. 국내 조선사들은 위 험 수준에 따라 3 단계 또는 5단계로 위험 등급을 표현하고 있다.

위험관리 단계에선 평가 등급에 따른 위험 작업이나 공정 에 대한 개선활동을 실시하고 결과를 검토하는 단계이다. 위 험성 불허 작업의 대책이나 위험성 수준을 감소시키기 위한 개선활동 등을 평가하고 조치하는 활동을 행함으로써 $\mathrm{PDCA}$ (Plan-Do-Check-Action) 순환과정을 통한 위험성 평가 의 효과를 분석하게 된다. 국내의 조선회사들은 위험성 평가 결과를 이용하여 공정개선과 연계하고, 개선활동의 효과를 
평가하는 체계를 갖추고 있다.

\section{Several Issues in Risk Assessment System}

\subsection{Issues in the existing system}

위험성 평가가 재해율의 감소와 안전문화 정착에 기여할 수 있다는 인식에도 불구하고, 조선업종에서 근로자 중심의 위험성 평가가 자리잡기 위해서는 아직도 업무절차 - 관리 · 통제 등의 시스템 자체와 문화적 인식을 바꾸는 과정이 필요 하다는 의견들이 존재한다.

현재 위험성 평가 관련 실무자들은 조선업종에서 위험요 인을 Figure 5 와 같이 근골격계질환, 작업환경, 직무 스트 레스, 작업 방법 순으로 여기고 있는 것으로 나타나고 있다 (Jeong, B.Y. et al., 2007a).

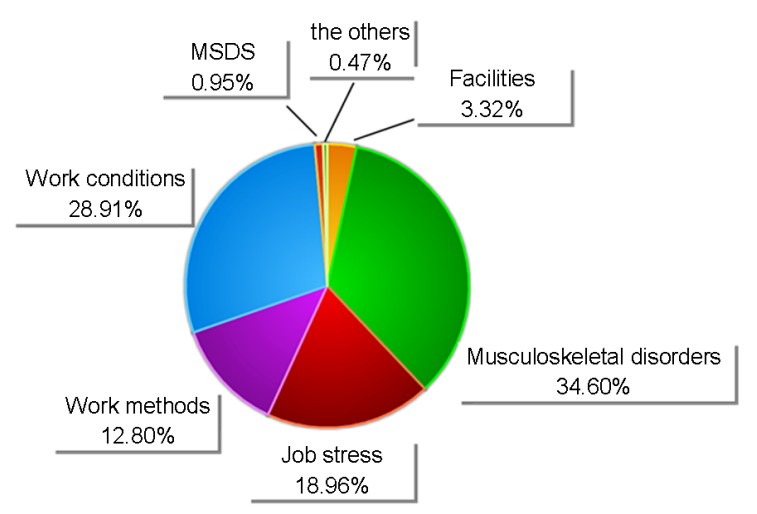

Figure 5. Risk factor in the shipbuilding industry

위험성 평가의 단계에서 실무자들은 Figure 6과 같이 위 험관리계획 수립, 위험요인의 파악, 위험성 평가, 작업활동 분류 순으로 적용의 어려움을 호소하고 있는 것으로 나타났

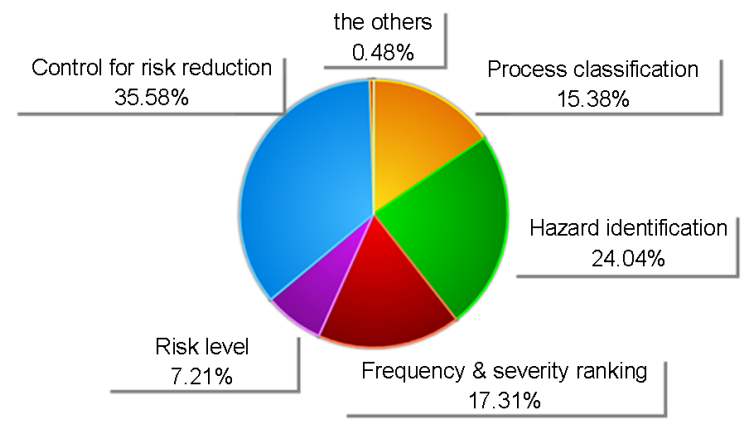

Figure 6. Difficulties in the risk assessment approach
다(Jeong, B.Y. et al., 2007a).

실무자들은 위험성 평가를 할 때 가장 어려운 점에 대하여 Figure 7 과 같이 전문지식의 부족, 평가 절차의 복잡성, 많 은 문서화 작업 순으로 어려움을 호소하는 것으로 나타났다 (Jeong, B.Y. et al., 2007a).

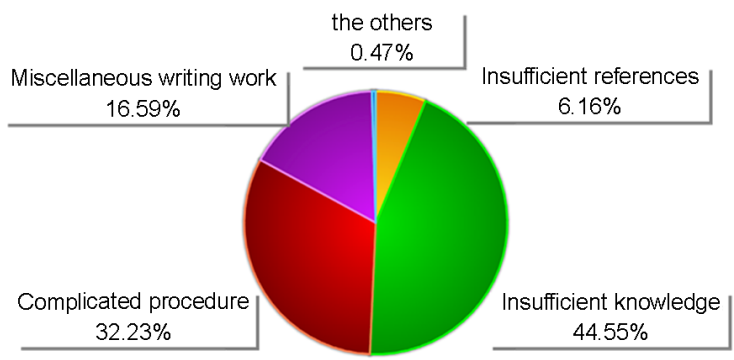

Figure 7. Problems in the risk assessment system

\subsection{Issues in the new system}

최근 위험성 평가제도의 도입에 관한 논의가 진행되면서 안전보건활동에서 새로운 제도도입에 관한 선행조건과 해결 하여야 할 과제들을 검토하여 볼 필요가 있다.

첫 번째는 시대에 맞는 안전보건에 관한 철학의 정립이 필 요하다. 시대적인 흐름을 고려할 때 안전보건활동은 근로자 중심, 수요자 중심, 탈규제로 요약할 수 있다. 우리 나라의 안전보건에 관한 법규나 제도를 조선업종 회사의 시각에서 보면 법규나 제도가 법을 집행하는 관리감독이자 중심으로 되어 있으며, 정부의 각 부처마다 각기 다른 통제수단으로 열거되어 있어 지키기 어렵고 힘들다는 의견들이 존재한다. 그렇다고 근로자의 입장에서 볼 때 법규들이 다 지켜지면 근로자의 안전보건이 모두 확보되느냐는 관점에서 보면 또 한 불만이 존재할 수 있다. 이런 문제들을 해결하기 위해선 현실적으로 모두 다 지켜야 할 안전보건의 객관적인 기준선 을 정하고 나머지는 노사자율의 위험성 평가제도에 맡기겠 다는 기본적인 합의가 노사를 포함한 정부 각 부처, 관련 관 리감독 기관 등으로부터 도출되어야 한다.

두 번째는 성과 중심의 안전보건활동으로 시스템이 변해 야 한다. 우리 나라는 안전보건 정책을 입안하는 전문가가 어느 분야에서 어떻게 활동하느냐에 따라 어느 분야는 과도 하리만큼, 어느 분야는 관리가 되지 않는 채로 시스템이 운 영되고 있다. 조선업종에서는 안전보건의 활동이 성과 중심 이 아닌 측정과 검사에 의존하고 있다는 점이 지적되고 있다. 성과 중심의 안전보건활동이 되기 위해선 관리감독을 담당 하고 있는 인력들의 전문성과 다양성이 요구되며, 안전보건 활동을 지원하는 행정체계도 꼭 지켜야 하는 안전보건의 기 
준선을 정하는 기능과 성과 중심의 활동을 평가하고 지원할 수 있는 기능이 갖추어지도록 재편되어야 한다. 즉, 회사에 서는 근로자의 안전보건을 확보하기 위하여 어떻게 활동을 하였으며, 어느 수준으로 성과를 내고 있는가에 대하여 관심 을 가져야 하며, 정부의 관리감독 기능은 사고가 나거나 직 업병이 의심되는 경우에 한하여 회사가 어떤 노력을 기울여 왔는가에 대하여 초점을 맞추도록 의식과 제도가 점진적으 로 변화될 필요가 있다.

세 번째는 현장 중심, 근로자 중심의 안전보건활동이 되도 록 환경이 조성되어야 한다. 위험성 평가제도가 정착되기 위 해서는 안전보건활동이 서류 작업에 그치지 않도록 하는 실 천적 접근을 위한 훈련과정이 필요하다. 근로자가 참여하지 않은 위험요인의 평가 및 개선안 도출은 비효율적이며, 개선 하기 쉬운 대안만을 해결하는 등의 형식적인 제도로 흐를 수 있기 때문이다. 따라서 현장 근로자가 위험요인을 인지하고, 안전한 작업을 할 수 있도록 다양한 사례 및 예시 등을 제공 하는 현장 중심의 교육이 필요하다. 또한, 위험요인을 제거 하는데 동참할 수 있도록 다양한 지원체계가 실제 작동할 수 있도록 배려되어야 할 것이다.

네 번째는 시행착오를 줄일 수 있도록 점진적이고 체계적 인 준비와 검토를 통해 위험성 평가제도가 정착되는 과정이 필요하다. 위험성 평가제도는 세부적인 규제보다는 포괄적인 규제방식을 추구하고 있어, 선진국과는 다른 법령체제 및 사 회적 의식 구조를 가진 우리나라에서는 충분한 검토를 거쳐 합리적으로 시행되어야 한다. 회사의 산재예방체제를 위험성 평가에 근거한 시스템으로 바꿀 뿐만 아니라 정부의 행정 감독 방식도 개별조항의 준수여부가 중점이 아닌 포괄적인 큰 그림에서 사업장을 지원할 수 있는 체계로 바뀌어야 한다. 또한 정부는 위험성 평가와 배치되거나 중복되는 제도나 걸 림돌이 될 수 있는 비현실적인 제도 또한 과감히 손질해야 하며, 시스템 자체와 더불어 문화적 의식이 전환되도록 노력 해야 한다.

\section{Conclusion}

본 연구는 문헌조사를 통하여 위험성 평가제도의 이론적 배경과 본질을 고찰하였다. 또한, 우리 나라의 조선회사에서 운영되고 있는 안전보건경영시스템하에서의 위험성 평가제 도의 현황을 조사하여 분석하고, 새로운 산업안전보건법상에 서의 사업주의 위험성 평가의무를 바탕으로 제도 도입에 따 른 선행조건과 해결하여야 할 과제들을 검토하였다.

조선업종의 위험성 평가제도는 회사별로 안전보건환경 경 영시스템의 인증을 위해 진행되고 있다. 위험성 평가의 두
축은 사업주의 위험성 평가의 의무와 근로자의 참여이다. 이 중에서 사업주의 위험성 평가의 의무는 법의 시행으로 도입 되었다고 볼 수 있으나, 근로자의 참여부분은 복잡한 절차와 현장 근로자들의 전문지식 부족 등의 이유로 완전하게 정착 되지는 않았다고 볼 수 있다.

인증의 요구조건이나 형식적인 서류상의 절차로 끝나는 위험성 평가제도가 되지 않기 위해서는 실질적인 평가에 도 움을 줄 수 있는 지원 시스템의 구축이 요구된다. 만일 지속 적인 지원 시스템이 가동되지 않는 경우라면 평가 절차는 단 순할수록 좋으며, 위험요인의 파악이나 대책에 노력이 집중 되어야 할 것이다. 또한, 정규직 근로자뿐만 아니라 용역 및 하청업체까지 포함하여 회사별 특성에 맞는 현장 중심의 노 력이 필요하다. 이를 위해 위험요인의 평가 및 등급 판정과 관련한 다양한 사례 및 예시 등을 제공하는 현장 중심의 교 육이 요구된다. 현장이 참여하지 않는 위험성 평가는 효과가 적은 비효율적인 대안만 나타날 수 있기 때문이다. 즉, 회사 의 규모나 근무 특성, 근로자의 구성 등을 고려하지 않는 일 반적인 위험성 평가 양식이나 절차의 강요는 시간과 노력이 낭비되는 비효율성을 가져올 수 있다. 따라서 조선업종의 위 험성 평가는 회사의 특성에 맞는 자율적인 평가 절차와 평가 기준에 따라 자율적으로 시행되는 것이 바람직하다. 마지막 으로 서류가 아닌 실천이 필요하다. 위험성 평가제도가 정착 되기 위해서는 서류 작업에 그치지 않는 실천이 필요하다. 실천하지 않는 위험요인의 평가 및 개선안 도출은 서류만 양 산하고 시간만 소모하기 때문이다. 따라서 현장 근로자가 위 험요인을 인지하고, 안전한 작업을 할 수 있는데 노력이 집 중되어야 할 것이다.

새로운 제도를 도입한다는 것은 변화를 의미한다. 제도가 도입되어 정착되기까지는 체계와 조직을 바꾸려는 다양한 노력들이 선행되어야만 한다. 또한, 시행착오를 줄이기 위해 선 다양한 시각에서 우리 나라의 상황에 대한 고려가 검토되 어 반영되어야 할 것이다. 본 연구는 위험성 평가제도의 도 입과 관련한 기초 자료로 활용될 수 있을 것으로 여겨진다.

\section{Acknowledgements}

This research was financially supported by Hansung University.

\section{References}

Chang, S. R., et al. Development of a Self-Audit Model for Hazard 
Assessment of Shipbuilding Industry, OSHRI Report 2008-101-1256, 2008.

Che, G. S., A Study on the Availability Prediction of Start-up Power Supply in Nuclear Power Plant by FTA Method, The Transactions of Korean Institute of Electrical Engineers, 48A(5), 517-523, 1999.

Chung, J. H., Kim, H. S., Choi, K. S. and Lee, Y. S., A study on the EPS Process of Quantitative Risk Assessment for the Safety Decision Making, Journal of the KOSOS, 14(2), 62-69, 1999.

Hong, S. M., Park, P., Kim, K. H and Sun, S. B., Case Analysis of Risk Assessment for Steel and Iron Works, Proceedings of the Safety Management and Science 2009 Fall Conference, 2009.

HSE, Five Steps to Risk Assessment, Health and Safety Executive, HSE Books, Sudbury, UK, 1998.

HSE, Review of Hazard Identification Techniques, Health and Safety Executive, HSE Books, Sudbury, UK, 2000.

HSE, Marine Risk Assessment, Health and Safety Executive, HSE Books, Sudbury, UK, 2002.

Jang, S. I., Lee, H. C., Jang, J. Y., Cho, J. H. and Kim, T. O., Cost-Benefit Analysis for Safety Management cost using Quantitative Risk Analysis, Proceedings of the Safety Management and Science 2001 Fall Conference, 2001.

Jeong, B. Y., et al. A Study of Risk Assessment System from an Appraiser Standpoint, Proceedings of the Ergonomics Society of Korea 2007 Spring Conference, 420-424, 2007a.

Jeong, B. Y., et al. Risk Assessment by Accident Types in a Shipbuilding Company, Proceedings of the Ergonomics Society of Korea 2007 Fall Conference, 2007b.

Jeong, B. Y., et al. Development of Risk Assessment Model in the Shipbuilding Industry, Korea Employers Federation, 2008.

Kim, G. H., Kwon, S. M., Lee, K. B., Kim, Y. S., Lee, J. W. and Kang, K. S., The Method of Risk Assessment by AMEA, Journal of the KOSOS, 9(2), 97-111, 2007.

Kim, D. H. and Lee, J. H., Qualitative Assessment for Hazard on the Electric Power Installations of a Construction Field using FMEA, Journal of the KOSOS, 19(4), 36-41, 2004.

Kim, J. G. and Chung, J. H., Risk Assessment System and Its Application for Complex Equipment, Proceedings of the Safety Management and Science 2004 Spring Conference, 2004.

Kim, T. O., et al. Development of the Occupational Safety \& Health Management System for Small \& Medium Enterprises, OSHRI Report 2007-95-1020, 2007.

Kim, Y. H., Kim, K. S., Yoon, S. R., Um, S. I. and Ko, J. W., Risk Assessment and Application in Chemical Plants Using Fault Tree Analysis, Journal of the Korean Institute of Gas, 1(1), 81-86, 1997.

KOSHIPA, http://www.koshipa.or.kr/, 2011.

KOSHA, 2010 Statistics on Occupational Injuries and Illnesses, KOSHA, 2011.

Lee, J. Y., et al. OSHRI Report 2010-62-868, 2010.
Lee, Y. S., et al. A Study on the Analysis of Effect for the Application of Risk Assessment, OSHRI Report 2007-99-1024, 2007.

Lim, H. K., Lee, K. T., Bae, D. C. and Chang, S. R., Development of a Voluntary Hazard Assessment Model for Small- and Medium-Sized Shipbuilding Plants, Journal of the KOSOS, 26(2), 70-76, 2011.

Park, D. Y., et al. Development and Introduction of an OSH Regulatory Framework Based on Risk Assessment for Korean OSH Regulation Systems and Policy, OSHRI Report 2009-117-1344, 2009.

Park, D. Y., et al. Future Direction and Development on OSH Regulatory Bodies and Administrative Organizations, OSHRI Report 2010OSHRI -994, 2010.

Seo, J. M., et al. Development of Risk Assessment System Model for Shipbuilding Industry, OSHRI Report 2007-57-928, 2007.

\section{Author listings}

Byung Yong Jeong: byjeong@hansung.ac.kr

Highest degree: Ph.D., Department of Industrial Engineering, KAIST Position title: Professor, Department of Industrial and Management Engineering, Hansung University

Areas of interest: Ergonomics, Prevention of Musculoskeletal Disorders, Safety Management

Woo Jin Kim: cufe00@nate.com

Highest degree: B.S., Department of Industrial and Management Engineering, Hansung University

Position title: M.S. Student, Hansung University Graduate School Areas of interest: Prevention of Musculoskeletal Disorders, Ergonomics, User Experience, Safety Management

Ye Seul Jeong: wjdtmf1227@hanmail.net

Highest degree: B.S., Department of Industrial and Management Engineering, Hansung University

Position title: M.S. Student, Hansung University Graduate School Areas of interest: Prevention of Musculoskeletal Disorders, Ergonomics, User Experience, Safety Management

Date Received : 2011-12-23

Date Revised :2012-01-11

Date Accepted : 2012-01-11 